\title{
Reconstruction of the Design of Children's Books in the Internet Period
}

\author{
Jurong Wang ${ }^{1, *}$ \\ ${ }^{1}$ School of Culture \& Media, Eurasia University in Xi'an, Xi'an, Shaanxi, China \\ *Corresponding author. Email: kuailejuzi168@163.com
}

\begin{abstract}
An excellent children's book is essential for children's growth. In the Internet era, children are more exposed to electronic products, which have a great impact on them. How to win the competition against electronic products, and how to stand out from the traditional publishing industry is a very important issue for children's book. The content and binding design of children's books in the digital publishing in the Internet era are elaborated, the existing problems are analyzed, and some solutions are proposed, in order to provide some suggestions for the traditional publishing industry in the publication of children's books.
\end{abstract}

Keywords: Children's books, Binding, Design, Innovation.

\section{INTRODUCTION}

The rapid development of new Internet media has seriously impacted the traditional books. However, challenges and opportunities always complement each other, and the digital publishing industry has also ushered in the peak of development, with various digital publishing products springing up and developing vigorously.

According to the 2019-2020 Annual Report on China's Digital Publishing Industry, China's digital publishing industry continued to develop healthily in 2019, with annual revenue exceeding 980 billion yuan. The emergence of a variety of digital products troubles traditional books. Many families are now faced with the dilemma of having their children read traditional books or electronic devices. However, in the end, parents often give in and children win electronic products. Some parents even give their children a mobile phone or tablet computer directly in order to prevent their children from crying. As a result, these electronic products occupy most of their children's time. The books therefore are of no use. How to liberate children from electronic products, how to let children like books, and how to let children like reading through books, is an urgent problem to be solved.

*Fund: This paper is the research result of the key course "Digital Media Editing" in Eurasia University in Xi'an (Project No. 2018KC009).
Among them, how to let children like books is a big problem, which should be analyzed from all aspects of the book itself. In any case, the audience of children's books must be children, so first of all, a targeted analysis of the characteristics of children should be made.

\section{CONTENT DESIGN OF CHILDREN'S BOOKS}

\subsection{All Kinds of Games Should Be Set up in Children's Books}

Games can promote children's growth and help them explore the world, which runs through the whole process of children's growth and life. They are in a period of rapid development of body, mind, and imagination, and enjoy imitating adults creatively or striving for the role they want through their imagination.

Children experience activities in games with sincere emotions and believe in the authenticity of fiction. At the same time, they can tell when something is fake. In a way, it is similar to the drama that reflects real life. In fact, the spirit of symbolic play embodies the characteristics of children's selfcenteredness and anthropomorphic animism. As Rousseau said, the child sees work and game in the 
same way. Game and work, like two sides of the same coin, have become inseparable. ${ }^{1}$

Games can help children to realize their own aspirations, a favorable emotional experience and self-identity.

Children should be given the freedom to choose books to promote their interests. Therefore, in addition to knowledge, gamification is a very important principle when it comes to the design of book content. Design should take into account the age characteristics of children. In addition, it is needed to design two different versions of the game for boys and girls, as they have different desires for the game. Most boys like hero dreams, all kinds of cars and so on; while most girls like dolls and have a princess dream. Kids will love content that is tailored to their own characteristics.

\subsection{The Content Design of Children's Books Should Be Consistent with Children's Psychology}

Toddlers love to play games. They use games to perceive the world and feel emotions. Publishing houses should also give consideration to games and the design of children's books, so that children can learn knowledge in the process of playing games.

A book that satisfies children's psychological characteristics is indeed bound to be a great success. The author's child is a typical example of someone who can spend an entire night doing math problems so that he won't sleep. In fact, he didn't want to do it at all. He just liked to peel off the stickers with the answers and stick them under the questions. A child of five or six is very fond of stickers. He will put stickers on walls, books, and tables everywhere. And the stickers in this book fit his interest. A child of five or six tends to be methodical and will not allow the wrong sticker on a book. For the sake of aesthetics, he has to calculate first and get the answer, and then remove the sticker.

Everyone aspires to perfection, and children are no exception. Seeing the outline of the dog in the English exercise book, children will try to put the other half complete, painted it with color, and complete the word.

First of all, the inner characteristics of children of different ages should be understood, and games should be designed according to these characteristics.

1. Ding Haidong, On Children's Play Spirit [J]. Journal of Shandong Normal University (Social Sciences), 2006, Vol. 51 (1): 8-12.
As long as children's psychology and interest are captured, they can firmly hold traditional books in their own hands.

\subsection{The Design of the Content of Children's Books}

The essence of any book is the content, and how to make the content more appealing to children is a question that children's book should consider. In the digital age, how to combine the content of books with digital to attract children's attention is particularly important.

Combined with children's physiological and psychological characteristics, some book manufacturers have made interactive experience books. On the one hand, children can realize emotional communication with children's books through sense of vision, touch, hearing and smell, and on the other hand, they can also mobilize children's participation in emotion and scene through clever design of content, so as to realize emotional experience at the practical level.

As for the visual, the designer can make a lot of shape on the page, such as pulling type, and rotating page. For example, a book can be designed in the shape of a car, with the child pulling a pull to move the book from the left side of the page to the right. In addition, some books can also be designed to be irregular shapes according to the content, some fold up and down, and some fold side to side. Children can pull apart the folded part when turning over the book, so that the content can be displayed on a page.

As for the sense of touch, some new materials are being used to make books. For example, there is a book about where the baby comes from, which makes use of three-dimensional materials and some special materials to make it very clear how the baby grows from a small sperm to a tadpole and slowly grows in the mother's stomach. In the book, the amniotic fluid in the mother's pregnancy belly is made of water. Children can see the baby's appearance in the amniotic fluid by vision, and touch the baby in the amniotic fluid. The baby is delivered through the vagina with a simple pull of the hand. The whole process is so clear that even 2-year-olds can see, touch and hear how they came to be. As a result, children are no longer confused about sex and where they came from. They don't feel embarrassed, but they know a lot of knowledge clearly through this way of perception. 
Through touch, the child's interest in reading can be increased, the experience of fun can be felt, and the child's curiosity can be satisfied.

As for hearing and smell, the designer applied some audio files into the book, and the sound will be produced when the hand is touched. For example, the sound wall chart such as baby know animal and baby know fruit on the market allows children to point to some animal, the wall chart will issue the pronunciation of the animal and the sound of the animal. The smell of the corresponding fruit is also included. In a book that teaches children mathematics, the number is presented in the form of treasure, children make a sound by touching the number, the scene of children into the treasure hunt, and understand the number in the scene and master this knowledge.

Good content design can bring better learning experience to readers. The digital age makes the traditional way of transferring knowledge through written narration unable to meet the needs of modern children. Pictures, texts, sounds, stereoscopic images, games and other content materials can be applied to a variety of content design, to provide children with all-round, multi-angle, three-dimensional, intelligent interactive experience and knowledge services. These books will make children perceive the world more frequently, enhance the enthusiasm of learning, improve the efficiency of learning knowledge, and bring better learning experience for children.

\section{BINDING DESIGN OF CHILDREN'S BOOKS}

For children's books, binding design is directly related to popularity and sales, so cover, color, illustration, font, and even binding method are worth paying attention to.

\subsection{Cover Design}

The cover design of a book is the key to attracting young children. Wang Renlu of the Republic of China once said about the cover design of children's books, "The appearance of children's books should have bright color and unique formats, so that children always have the tendency to look at them at the first sight" 2 "It is better to use images for the cover to show the characteristics of the book." 3 "Children

2. Wang Renlu. Classification and Selection of Children's Books [J]. Educational Journal, 1929, 21(12): 72-79.

3. Zhu Zaiqin. What kind of children's book is suitable for the semi-monthly journal for further education [J].1936, 5(10):5152 . have a special attachment to pictures. The combination of words and pictures makes children see the pictures and arouse the need to read." ${ }^{4}$ The book cover should be designed according to children's characteristics.

As children cannot read and write, pictures and graphics have become the most important way to convey information to children. A baby bear occupies the whole cover, and looks ingenuous; or a chicken catching bugs taking over the page and so on. Such covers aimed at young children are very popular.

\subsection{The Appearance Design of Children's Books}

The most important thing for a book is its cover. Just like a person's first impression, there is little innovation in the appearance of traditional books. Most books are rectangles with pictures and words on the cover, and some may use big pictures to attract the audience's attention.

Some designers who study infant psychology also design reading materials suitable for infant psychology. Traditional folio books for children range from 16 to 124 and are basically rectangular or square. However, the appearance of children's books on the market is no longer limited to the traditional rectangle. At present, there are square, oval, round, triangle and other shapes, which are more lively and lovely.

In addition, there are some special shapes, such as cars, small mushrooms, various small animals, and even handbags. Most of these books are aimed at young children, who can have fun while learning. For example, the book "Please Help the Tiger with Tooth Extraction" published by Zhejiang Children's Publishing House looks like a pair of gloves, which is very creative.

Children's books in the Internet age need to take many forms to appeal to children. Children like games, like to communicate with the book, so the three-dimensional book, from the cover, images, to the content, have adopted the practice of text with three-dimensional patterns.

Children's books in the Internet age need to take many forms to appeal to children. Children like games, like to communicate with the book, so the three-dimensional book, from the cover, images, to

4. Zheng Zhenduo. The teaching method of children's literature [A]. Edited by Wang Quangen. Selected essays on modern Chinese children's literature [C]. Nanning: Guangxi People's Publishing House, 1989: 215. 
the content, have adopted the practice of text with three-dimensional patterns. Another example is the ocean series, which is a handmade three-dimensional book, in which the animals, characters are in line with the characteristics of children's hearts.

\subsection{Inside Page Design of Children's Books}

The traditional children's books are full of rules, and the design of the cover, folio and inner pages is a rectangle or square.

At present, the children's books on the market are no longer limited to the traditional rectangle or square, but are designed according to the contents of the books. For example, the series of "Chicken Ball" involves games that cannot be displayed on one page. When children read the game, the game panorama can be displayed in front of them as soon as the folding is opened. Another example is the dog, cat competition tree climbing, the panorama of the tree is made up of three fold, children will open the fold up and down to see the panorama of the tree. The tail of the cat playing hide-and-seek is covered by a small fold. The fold is opened, and the tail and the cat fit. The same book can be designed according to the content, just to meet the curiosity of children, which is suitable for children to explore in the game.

\subsection{Color Design of Books}

Color is a kind of recessive language, which is especially true in the design of children's books. On the one hand, color adds beauty to the appearance of children's books, foil the atmosphere of the content, and render emotion; On the other hand, the application of color can also reflect the aesthetic of children's books, strengthen the visual expression of books, and inspire children to read.

Children are in a period of rapid development in psychology and physiology, and their cognition of external colors is not the same. Children are generally more sensitive to bright colors, and love colors with high saturation and strong contrast. They are easy to distinguish and remember bright colors with high purity such as red, yellow and green. They make choices based on the bright colors they see.

Among the various elements of books, color is the most attractive element for children. Their cognition of books is often perceived according to color, which can stimulate children's interest in books.

At present, the market for children's books in China seems to thrive, which makes parents confused. As for the color, the color of some books is more messy, just a variety of colors of simple piling and mixing without a sense of beauty, which will make children's cognition of color, and aesthetic ability decline.

\subsection{Material for Children's Books}

In the history of book publishing, there were many kinds of writing materials, such as tortoise shell, brass bell, bamboo, clay, etc., due to various restrictions. Later Cai Lun improved paper, making it one of China's four great inventions.

Now, in order to truly achieve experiential learning, the production of children's books adopted a variety of materials. In addition to traditional book made of paper, there are books made of sheepskin, silk, bamboo, and cotton.

This is a typical example of how young children learn about the outside world through eating. Some designers make cloth books out of soft cotton cloth, and such indestructible "cloth books" are specifically aimed at young children. The cover and content of the book are all made of cotton cloth, and the content contains simple words and pictures. All the threedimensional shapes of the picture are made of cotton cloth, which children cannot tear.

There are books made of sand, which is covered with a layer of transparent and strong film. The graininess of sand can be distinctly felt when touched. In addition to solid materials, some liquid materials in reality are also applied to book, such as the previously-mentioned book about the growth of a baby in the mother's belly, in which the amniotic fluid is made of water, coated with a thick film. It feels soft and smooth, just like real amniotic fluid.

These books are designed to take into account the physical and psychological characteristics of children, immediately winning the love of parents and children.

Some publishers are also offering DIY handmade books that can be made from a variety of materials. The books made of these special materials meet the different needs of children, reflecting the particularity of different materials, and children are more cognitively clear.

\section{EXISTING QUESTION}

\subsection{Same Style and Lack of Innovation}

The digital age has brought a great crisis to children's book publishers. Some children's books 
have begun to innovate, and the children's books designed are more wonderful and detailed than before, both in form and content. However, children's books, whether literary or other categories, mostly employ bright color with no innovation.

The problem of homogenization of children's books in major bookstores is obvious, with similar style and lack of innovation.

\subsection{High Cost}

The diversity of children's books in appearance, shape and so on provides nutrition for children's growth. These books are expensive. A 16-page, A6 book made of cloth costs more than 30 yuan. The price of a 20-page, A4 pop-up book is about 180 yuan. Some books made of special materials cost more than 200 yuan, which is still a little expensive for ordinary people. If you can reduce the production cost, suitable for the general audience, is the biggest good thing. Production costs must be reduced to make it suitable for the general audience.

\subsection{Monotonous Interactive Design}

In terms of interactivity, there are many innovations in the design of children's books. In the design of the inside pages, a lot of cross-pages are designed according to the content of the books, lacking interactivity though.

The design of children's books can also be more gamified, so that children can roam in the gamified books, and they will certainly give up electronic devices including mobile phones and tablets. This requires a joint effort between publishers and parents.

\subsection{Insufficient Cognitive Stimulation in Content Design}

Children use cognition and memory when reading books. But books only tell children the color and shape of things, and do not inspire children to participate in these cognition. An excellent book will stimulate children's imagination, reasoning and various wonderful experiences in the design of the content. When children open the first page, they urgently want to know the scene of the story and speculate the ending of the story.

The content design of children's books in the market is mainly based on cognition, and the design of stimulating children's imagination and reasoning needs to be improved.

\section{SOLUTION}

As a spiritual and cultural product, the main function of books is to spread knowledge. An excellent children's book has many characteristics, and some problems can be considered from the following aspects:

\subsection{The Structure Design Is Complex and the Packaging Is Exquisite}

The first thing that attracts young children must be packaging. Children's books should be designed with diversified contents. Illustrated books should be visually innovative. Books with different forms and attractive appearance are easy to attract mothers and children and arouse their interest in reading.

\subsection{Cover and the Color of the Magazine Is Gorgeous But Not Conventional}

The design of children's books should value the collocation of colors. Red, yellow, green and other bright colors with strong contrast are commonly used to adapt the colors to children's psychological characteristics, give children color concept and cultivate their aesthetics. Type, paper, binding should also meet the characteristics of children.

\subsection{Content Design Stimulates Children's Cognition}

The content design of children's books should arouse children's curiosity and exploration spirit and attract their attention. The story content should also have certain predictability and be able to communicate with young children. Children learn knowledge through play that is deeply embedded in their minds.

\subsection{Lowering the Price}

Books are too expensive because of their design. Therefore, it is necessary to find ways to reduce the production cost of children's books, or to price ordinary books more suitable for ordinary people, rather than discount on the high price. Eliminating the discount process and directly providing the price that ordinary people can accept should be of great help to the issue of children's books.

Only in this way can the characteristics of children's books be obvious and children can really be separated from electronic products. 


\section{CONCLUSION}

The importance that publishing houses attaches to the audience in the Internet era, the fierce competition between electronic products and traditional books for audience, and children's physical and mental characteristics make it easier for them to accept electronic products. Therefore, separating the children from the electronic products requires the joint efforts of all sides.

The market for children's books should be captured. Children's psychological and physiological characteristics should be taken into account to develop a variety of options. The collocation of color, the production of appearance, the selection of content and materials should be considered to form the multidimensional design of vision, touch, hearing and smell, so as to form the interactive experience with children and fundamentally meet the needs of children. Only in this way can we achieve results. Children's books should be reasonably designed combined with children's feelings, in a bid to better play the role of information transmission.

\section{AUTHORS' CONTRIBUTIONS}

This paper is independently completed by Jurong Wang.

\section{REFERENCES}

[1] Wu Yan. Children's Game Spirit and Children's Book Design [J]. Art Panorama, 2013 (24). (in Chinese)

[2] Yue Yue. The application of interactive design in children's books [J]. Editors Friend. 2014, 6.P90-92. (in Chinese)

[3] Jiang Zhe. On the interesting design of modern children's books [J]. Popular Literature and Art, 121. (in Chinese)

[4] Li Yingrui. Analysis of the application of interactivity in the design of children's books. (in Chinese)

[5] Song Qiwei. Study on the design of children's books under the visual and tactile form. (in Chinese)

[6] Wei Yixiao. Analysis of the current situation and creative research on the design of children's books $[\mathrm{J}]$. Journal of Beijing Forestry University, 2011 (24). (in Chinese)
[7] Yang Na. Research on the Sentimentalization of Children's Books [J]. Journal of Southwest Jiaotong University (Social Sciences), 2012 (12). (in Chinese)

[8] Hao Huairu. Research on the three-dimensional binding design of children's books [J]. Journal of Shanxi University (Philosophy and Social Science Edition), 2013 (8). (in Chinese)

[9] Wang Renlu. Classification and Selection of Children's Books [J]. Educational Journal, 1929, 21(12): 72-79. (in Chinese)

[10] Zhu Zaiqin. What kind of children's book is suitable for the semi-monthly journal for further education [J].1936, 5(10):51-52. (in Chinese)

[11] Zheng Zhenduo. The teaching method of children's literature [A]. Edited by Wang Quangen. Selected essays on modern Chinese children's literature [C]. Nanning: Guangxi People's Publishing House, 1989: 215. (in Chinese) 